\title{
Role of Structural Dynamics in Leukocyte Integrins Function: Interplay between the Shape-Shifting Mechanism and Allostery
}

\author{
Pragya Manandhar, Omar Abousaway, Trevor Le and Mehmet Sen* \\ Department of Biology and Biochemistry, University of Houston, USA
}

Submission: September 21, 2017; Published: October 26, 2017

*Corresponding author: Mehmet Sen, Department of Biology and Biochemistry, University of Houston, Houston, TX, 77204, USA, Email: msen@uh.edu

\begin{abstract}
This review concerns the recent progress on structural characterization of leukocyte integrins. Leukocyte integrins, also called CD18integrins, are exclusively expressed on the leukocyte cell surface and modulate their trafficking in vasculature. Therefore, these integrins are major drug targets in autoimmune pathologies. Through initial drug development efforts, Efalizumab (Raptiva), designed to antagonize ligand-affinity of the LFA-1 integrin, was initially approved and originally marketed to treat psoriasis. However, the FDA and European Medicines Agency recommended suspension of Raptiva due to risk of progressive multifocal leukoencephalopathy (PML) as a result of immune suppression and concomitant activation of John Cunningham virus. In short, there is still an urgent need to design 2nd generation of anti-inflammatory drugs. Therefore, recent structural studies on leukocyte integrins, which have depicted unprecedented local and global motions, could be beneficial in the structure-guided drug design strategies..
\end{abstract}

Keywords: Integrins; Allostery; Protein dynamics

\section{Introduction}

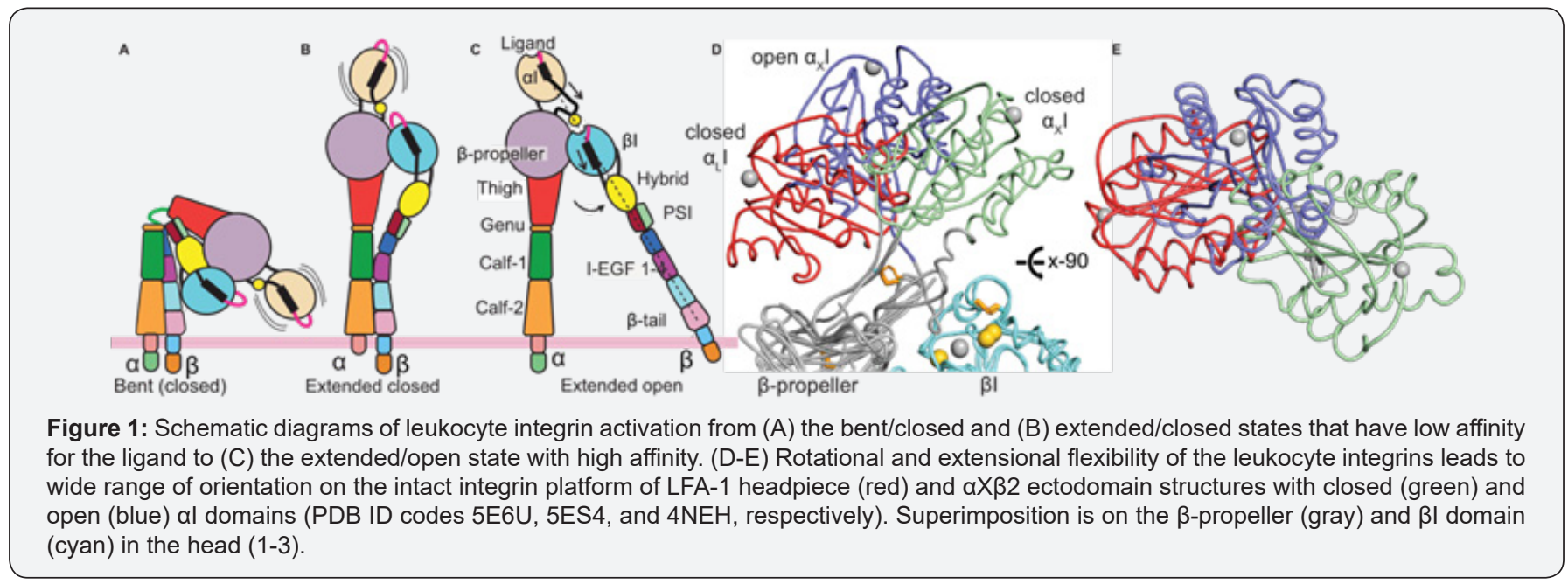

The integrin family consists of 24 type-I transmembrane receptors that form $\alpha / \beta$ heterodimers. Half of them bind to the extracellular ligands through an inserted $(\alpha \mathrm{I})$-domain. Crystal structures of $\alpha \mathrm{I}$-domains revealed a compact fold that contains a central parallel beta-strands which are sandwiched by amphipathic $\alpha$-helices. Recent structural work on the $\alpha \mathrm{I}$ - domain containing integrins has informed a great deal about how these allosteric protein machines regulate bidirectional cellular signaling through the cell membrane, allosteric crosstalk between $\alpha / \beta$ heterodimers, and ligand affinity [1-3]. While conformational alterations of integrin ectodomain in the scale of $200 \AA$ are responsible for transferring cellular signaling through 
cell membrane (Figure 1A-1C), flexibility of the $\alpha \mathrm{I}$-domain on the intact platform and dynamics of its secondary structures drive the communication between $\alpha / \beta$ heterodimers and ligandaffinity (Figure 1D-E). Thus, structural dynamics at overall ectodomain and individual domain levels appears to regulate integrin function on cell surfaces.

\section{LeukocyteIntegrin Structure}

Leukocyte integrins are formed by one of the four $\alpha$-subunits $(\alpha \mathrm{L}, \alpha \mathrm{M}, \alpha \mathrm{X}$ and $\alpha \mathrm{D})$ and a $\beta 2$-subunit. Structural studies mostly by negative electron microscopy revealed three overall conformational ensembles of leukocyte integrins [5-8]. In the quiescent form, leukocyte integrins adopt a bent/closed state (Figure 1A). One of the two critical motions is integrin extension, which occurs at the $\alpha$ and $\beta$ knees and allows leukocyte integrin to move its ligand-binding domain away from the cell membrane by about $200 \AA$ (Figure 1B). While inducing a standing conformation, this motion is not sufficient to move integrin to the high affinity state. Requirement of high ligand-affinity comes from the second motion, called headpiece opening [9]. Swing-out of the hybrid domain relative to the $\beta I$-domain in the $\beta 2$-subunit requires a high affinity $\beta \mathrm{I}$-domain (Figure $1 \mathrm{C}$ ). This motion facilitates $\beta \mathrm{I}$ domain interaction with the $\alpha \mathrm{I}$-domain located the $\alpha$-subunit. Indeed, this crosstalk mechanism, despite being postulated more than two decades ago, recently was crystallosgraphically proven correct [2].

\section{The aI-domain}

All four subunitsof leukocyte integrins have an $\alpha$ I-domain that buds out from a classical seven-bladed $\beta$-propeller domain and critically engages extracellular ligands (Figure 1A). Ligand binding to the $\alpha \mathrm{I}$-domain is modulated by the Mg2+ located in the Metal Ion Dependent Adhesion Site (MIDAS). In our earlier work, an integrin homolog, Pactolus, which has an imperfect MIDAS with a single mutation, lost its ability to bind to the divalent cation, suggesting the ligand-engagement is not modulated through pactolus I-domain [10]. In more general perspective, homologs of the $\alpha \mathrm{I}$-domain are found in collagen-binding integrins and the force-sensing A-domains in von Willebrand factor, to microorganisms ranging from metazoans to agnathostomes [11]. Therefore, further research is needed to elucidate differencesin $\alpha \mathrm{I}$-domain structures, how these differences relate to their affinity to divalent cationand extracellular ligands, and if and how these differences result in functional divergence.

\section{Flexibility of the Ai-Domain}

In recent intact integrin structures, the $\alpha \mathrm{I}$-domain is indeed positioned in multiple poses on the integrin platform but, its spatial positions in multiple crystal lattices (Figure 1D-1E) [1-3] and negative-stain electron microscopy (EM) images are enforced by crystallographic lattice contacts or EM carbon-grids $[5,6]$. In fact, some crystal structures does not show any electron density for the $\alpha$-domain despite the presence of the $\alpha$ I-domain in the crystallized protein solution [3], suggesting of averaging of local density due to the $\alpha \mathrm{I}$-domain exploring multi-conformation in crystal lattice. Overall, this suggests a high flexibility of the $\alpha \mathrm{I}-$ domain on the intact integrin platform.

Remarkably, the $\alpha$ I-domain is limitedly expressed in metazoans, therefore having a flexible $\alpha$ I-domain might be advantageous over integrin-class that lacks the $\alpha \mathrm{I}$-domain. Given that the $\alpha \mathrm{I}$-domain integrins appear to interact with ligands in highly inaccessible environment, such as collagens in bundles (integrins $\alpha 1 \beta 1, \alpha 2 \beta 1, \alpha 10 \beta 1$, and $\alpha 11 \beta 1$ ), adhesion molecules on cell surfaces (integrins $\alpha \mathrm{L} \beta 2$ and $\alpha \mathrm{E} \beta 7$ ) and foci of complement molecules deposited on pathogenic surfaces (integrins $\alpha \mathrm{X} \beta 2$ and $\alpha \mathrm{M} \beta 2$ ), there are still many questions on role of conformational changes on integrin activation, to what extent does the $\alpha$ I-domain flex when unbound and bound to a ligand? How does the overall shape of the integrin alter the $\alpha \mathrm{I}$ domain flexibility in the intact integrin platform?
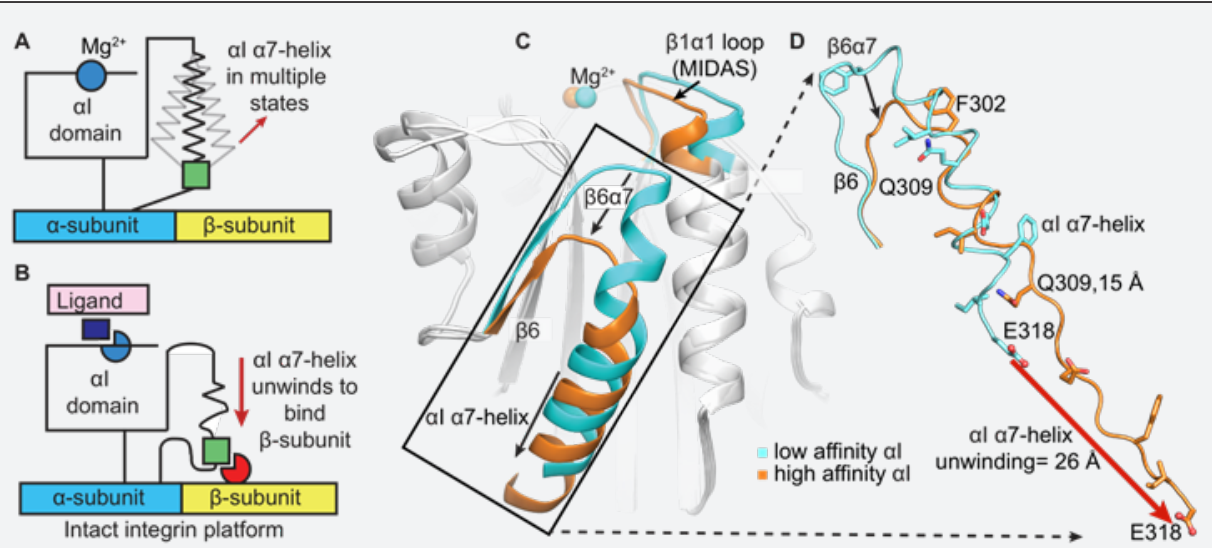

Figure 2: Schematic diagrams of the $\alpha$ l $\alpha$ 7-helix during the integrin activation from (A) the closed/low affinity states to (B) open/high affinity states. The $\alpha \mathrm{l} \alpha$-helix populates many conformations in the (A) closed state, and its interaction with the $\beta 2$-subunit reduces the size of the conformational ensemble. (C) Observed conformational changes of the isolated-closed and open al-domains. (D) Structural motion around the allosteric al $\alpha 7$-helix differs on the intact integrin platform as observed in our recent crystal structures. 


\section{Activation of the aI-domain}

Ligand-binding to the $\alpha$ I-domain requires a reorganization of the Mg2+-binding motif on top of the $\alpha \mathrm{I}$-domain that is allosterically coupled to the downward axial motion of the $\alpha \mathrm{I}$ $\alpha 7$-helix along the side of the domain [2] (Figure 2A-B). NMR $\mathrm{H} / \mathrm{D}$ exchange, heteronuclear cross relaxation $1 \mathrm{H}-15 \mathrm{~N}$ NOE have suggested that the $\alpha \mathrm{I} \alpha 7$-helix is highly dynamic [12]. Molecular dynamics and normal mode analysis $[13,14]$ have implicated that the downward movement of the $\alpha \mathrm{I} \alpha 7$ helix is a result of its intrinsic flexibility. However, no studies have provided any experimental data for the ensemble nature of integrin allostery in both fast and slow molecular motion regimes, or for how allosteric coupling between the Mg2+-binding site and the $\alpha \mathrm{I} \alpha 7$ helix is altered by a divalent cations or small molecule agonist and antagonists. Crystallography failed to probedynamic motions of $\alpha \mathrm{I}$-domain secondary structural elements critical in coupling MIDAS and the allosteric $\alpha$ I $\alpha 7$-helix in both fast and slow molecular motion regimes in solution. In hundreds of $\mathrm{X}$-ray structures of $\alpha \mathrm{I}$-domains that are free or bound to ligands and small molecules, positions of the allosteric $\alpha \mathrm{I} \alpha 7$-helixand depends on crystal lattice contacts and thus differ remarkably (Figure 2C) [1]. Indeed, the allosteric $\alpha \mathrm{I} \alpha 7$-helix on intact integrin platform loses much of its helicity when adopting the open state and reshapes to an "internal ligand" to relay cellular signaling between integrin heterodimer (Figure 1C \& 2D). We predict that a thermodynamic equilibration between the closed and open states of the $\alpha$ I domains occurs even in the absence of the ligand because of the highly flexible and dynamic $\alpha$ I $\alpha 7$-helix and the Mg2+-binding site to which it is coupled. In other words, it is logical to consider that the $\alpha$ I open state is potentially a higher energy state and has a more limited ensemble of conformations than the $\alpha$ I closed state, yet exists even in the absence of the ligand (Figure 1C \& D). Hence, further biophysical approaches is immediately needed to define molecular basis of the $\alpha \mathrm{I}$-domain activation in solution and thermodynamic equilibrium that modulates it.

\section{Conclusion}

A closer look at the sequence of mechanistic and structural dynamics events at macroscopic (overall integrin conformational changes on cell surfaces) and microscopic (secondary structure motions at different time regimes) levels preceding leukocyte integrin activation is essential for understanding the ensemble nature of integrin allostery and function. This provides insight into its structure-function relationship, a more thorough understanding of the design and development of 2 nd generation novel anti-inflammatory inhibitors for curtailing autoimmune pathologies. Therefore, our approach in this proposal has a high potential to help fine-tune functions of myeloid cells and to lessen immune hypersensitivity and autoimmune pathologies while mitigating the risk of global immune suppression.

\section{Conflict of Interest}

Authors declares no conflict of interest regarding this publication.

\section{References}

1. Sen M, Springer TA (2016) Leukocyte integrin alphaLbeta2 headpiece structures: The alphaI domain, the pocket for the internal ligand, and concerted movements of its loops. Proc Natl Acad Sci USA 113(11): 2940-2945.

2. Sen M, Yuki K, Springer TA (2013) An internal ligand-bound, metastable state of a leukocyte integrin, alphaXbeta2. J Cell Biol 203(4): 629642 .

3. Xie C (2010) Structure of an integrin with an alphal domain, complement receptor type 4. The EMBO journal 29(3): 666-679.

4. Hynes RO (2002) Integrins: bidirectional, allosteric signaling machines. Cell 110(6): 673-687.

5. Chen X (2010) Requirement of open headpiece conformation for activation of leukocyte integrin alphaXbeta2. Proc Natl Acad Sci, USA 107(33): 14727-14732.

6. Chen X, Yu Y, Mi LZ, Walz T, Springer TA (2012) Molecular basis for complement recognition by integrin alphaXbeta2. Proc Natl Acad Sci, USA 109(12): 4586-4591.

7. Nishida $N(2006)$ Activation of leukocyte beta 2 integrins by conversion from bent to extended conformations. Immunity 25(4): 583-594.

8. Adair BD, Xiong JP, Alonso JL, Hyman BT, Arnaout MA (2013) EM structure of the ectodomain of integrin CD11b/CD18 and localization of its ligand-binding site relative to the plasma membrane. PloS one 8(2): e57951.

9. Schurpf T, Springer TA (2011) Regulation of integrin affinity on cell surfaces. The EMBO journal 30(23): 4712-4727.

10. Sen M, Legge GB (2007) Pactolus I-domain: functional switching of the Rossmann fold. Proteins 68(3): 626-635.

11. Whittaker CA, Hynes RO (2002) Distribution and evolution of von Willebrand/integrin A domains: widely dispersed domains with roles in cell adhesion and elsewhere. Mol Biol Cell 13(10): 3369-3387.

12. Legge GB (2000) NMR solution structure of the inserted domain of human leukocyte function associated antigen-1. J Mol Biol 295(5): 1251-1264.

13. Gaillard T (2007) Comparative normal mode analysis of LFA-1 integrin I-domains. J Mol Biol 374(1): 231-249.

14. Nam K, Maiorov V, Feuston B, Kearsley S (2006) Dynamic control of allosteric antagonism of leukocyte function antigen-1 and intercellular adhesion molecule-1 interaction. Proteins 64(2): 376-384. 
(C) Commons Attribution 4.0 Licens
Your next submission with Juniper Publishers will reach you the below assets

- Quality Editorial service

- Swift Peer Review

- Reprints availability

- E-prints Service

- Manuscript Podcast for convenient understanding

- Global attainment for your research

- Manuscript accessibility in different formats

( Pdf, E-pub, Full Text, Audio)

- Unceasing customer service

Track the below URL for one-step submission https://juniperpublishers.com/online-submission.php 